\title{
THE INFLUENCE OF KNOWLEDGE MANAGEMENT ON THE DEVELOPMENT OF INNOVATION IN THE ENTERPRISES IN THE REPUBLIC OF NORTH MACEDONIA-SELECTED RESULTS
}

\author{
Marija Pendevska ${ }^{1}$
}

DOI: https://doi.org/10.31410/ITEMA.2020.185

\begin{abstract}
Business community faces rapid change due to the technology development. Its influence on business environment causes change in the knowledge base and its possibilities on achieving new solution as innovation thus gaining new knowledge. Enterprises are managing these continuous changes using the knowledge of its unique set of enterprise's knowledge infrastructure, employee's knowledge skills and business environment. This implies that fast knowledge development from technology development and innovation makes high pressure on the enterprises and on its employees as well. The manner how this is used and utilized within enterprise becomes dominant challenge for every enterprise and its respective management globally. Many researches in the past years have shown that innovations as commercialisation of new knowledge development and knowledge management practices can assist facing those challenges remarkably. Creating the balance between them is unique for every enterprise, for every respective management.

This research paper consists of the following parts: introduction, selected theoretical and empirical framework and conclusion.

The theoretical framework gives selected overview of the relevant researches in the field of knowledge management and innovation and their respective interrelation in new knowledge creation and commercialising of this new knowledge as innovation.

The empirical framework describes the research design and gives the selected results obtained through the research of selected enterprises based on Questionnaire that covers key parameters previously discussed in the theoretical framework. Research focus is measuring the existence, the exchange, the creation of knowledge within enterprises and its usage in terms of new product development and/or improved products of the respective enterprises. Finally, in the conclusion, the study results are elaborated and their contribution to the existing body of knowledge and industry practices is discussed.
\end{abstract}

Keywords: Knowledge management, New knowledge creation, Innovation, Open innovation, Closed innovation, Radical innovation, Incremental innovation.

\section{INTRODUCTION}

7 he purpose of this paper is to explore the readiness of enterprises to work with the challenges of a globally connected economy, which is pushing / demanding continuous development of both individual knowledge and knowledge of the enterprise, pushed into ever changing market by constantly generating new products, improved products and services that arise from the application of new knowledge in enterprises. This signifies finding and maintaining the delicate balance of knowledge and knowledge flows in the enterprise, on the one hand, by creating own new knowledge in the enterprises and, on the other, tracking

1 Komercijalna Banka AD Skopje, ul. Orce Nikolov br. 3, 1000 Skopje, R. North Macedonia 
outside knowledge and market needs by continually adapting the products, processes and services required by users, customers, partners.

The purpose of this research is to enlighten the elements that enable enterprises to apply appropriate knowledge management practices, as well as to enhance understanding of how these practices impact the development of new products and services in the form of successful enterprise innovations.

\section{THEORETICAL BACKGROUND}

Nowadays, there is high demand on skilled workers and flexible enterprises that are willing to invest in their development. Technological progress and globalization are widening the gap between developed countries and others by automating and digitizing services and production. Technological progress in practice replaces the workforce. Global trade and investment flows are homogenizing production flows, and this puts pressure on companies and workers to compete in global markets. If they do not incorporate and adopt the high capability and competitiveness of their enterprises, they simply lose the edge and are left behind. This research aims to enhance the capabilities in terms of knowledge and innovation in enterprises, in order assist them to work with the pressures of global challenges and changes.

According to Schumpeter's description, innovative competitiveness is the engine of economic development and prosperity. New products and services increase the labour productivity of innovating enterprises by changing the distribution of labour nationally and internationally (cited in Witt, 2016; Metcalfe et al. 2006).

This research is in terms of knowledge flow in the enterprise, i.e. the existence / exchange / creation of knowledge in the enterprise and the relation between knowledge management and the creation and application of new knowledge, i.e. how the enterprise applies / uses knowledge in the form of radical, disruptive new or incremental, improved products / services or processes. This applies both to products and services from the same enterprise, made independently with internal knowledge, and to products and services that result from external knowledge collaboration in the form of collaboration with the university, the user, and other enterprises. Knowledge is a value embedded in a product / service / process and stays in the enterprise; depending on how it is used further on, the intensity/persistence of the innovation activity within the enterprises is, whether the knowledge creation cycle stops with the realization of single product/service or continues through controlling and monitoring through the product life. The research herewith is looking for answers to how enterprises in the Republic of $\mathrm{N}$. Macedonia add new value through their operation. Is the innovation process open semiopen or closed, using own knowledge, semi-open, cooperating in gaining new knowledge and incorporation of outside knowledge within the enterprise, in order to adjust / improve products / services, what novelty bring their respective innovative product, service or process that is being realised?

The only resources that cannot simply be replaced or imitated are individual work professionals and their skill and overall knowledge along with their interaction and successful integration throughout the enterprise. Their unique knowledge is what makes the difference of enterprises. It is the different knowledge structure and enterprises readiness for further knowledge expansion, which over certain a period of time explains the different speed in developing appropriate solutions for different enterprises. 
Employee knowledge can be explicit, easily recognizable and transmitted, both through personal contact and through other synchronic or asynchronic communication channels, such as through picture, audio and video, chart, sketch etc. text or table. It can also be tacit knowledge, unconscious knowledge. Both forms make the basis for the total knowledge (learned theoretical and experiential knowledge) that is unique to every individual, and is different, some of it not conscious (if conscious, it could be transmitted), simply obtained by working on a particular activity or pursuing particular interest.

The duration of the cognitive process is personal feature, some individuals learns faster, some need more time for creating deeper understanding. This indicates that the personal characteristics of the employee are important for the environment, since it is the essence of their full involvement and further engagement in the work in the enterprises. This indicates that for smooth transfer of necessary knowledge within or into the enterprise, there is a need of developing working environment that fosters smooth exchange with individuals, groups, where the inexperienced is ready to learn and apply knowledge and the reverse, the more experienced ready to transfer and share necessary knowledge. Previous large experience can sometimes be an obstacle to learning new skills, especially when changing new technologies or work processes, but sometimes it is crucial in recognizing the operation patterns. It means fostering work environment that nurtures employees' willingness to learn, whether by working or exploring new methods of work, that is, to track the results of work, to control and monitor of applied solutions, concepts that facilitate, trying to simplify the work bottlenecks.

Since knowledge is not a value if it is not used, the key interest is whether and how knowledge within enterprises is used in building new value for the enterprise.

The enterprise in which this is achieved is a prepared one. It adds value, knowledge is continually built and engaged, by everyone in the enterprise (sometimes using outsourced solutions, but in their own implementation, the so-called semi-open or open innovation system). Knowledge can enter from various sources; every effort to add value is welcome. Self-engagement and willingness to acquire exchange and re-apply knowledge is becoming crucial capability at the individual and organizational level.

As long as the enterprise nurtures its persistence in innovation activities, new knowledge, an idea / solution, the likelihood of new product / service / process occurring, and the knowledge of how it is achieved, even if it is discarded and isolated, brings value for the enterprise; the knowledge how to get there remains in the enterprise and can be used for a new cycle of innovation.

\section{Enterprise Knowledge Management Framework}

Selected elements of knowledge management practices that foster knowledge development and the emergence of new knowledge within enterprises are identified and in detail analysed, being observed through the implementation of innovative products / services / processes and their respective novelty implemented by enterprises.

The current state of the art of technology solutions are simplifying workflows and increasing efficiency, but building organizational and human readiness throughout this ever-changing process is an even greater challenge for any enterprise. Some companies do better than others, and this is clearly reflected in their persistence and readiness to introduce new products and services, or to introduce customizations of existing products / services. Therefore, a key 
element is to establish a genuine attitude in the enterprise towards knowledge sharing and applying it in new knowledge development. According to Desouza (2003) "The biggest obstacle to effective knowledge management is not the realization of the latest ICT solutions, but the failure of the preparation and readiness of the people involved in the process to share their know-how (Desouza, 2003). Monitoring and guiding change and engaging the people involved is the key to make the change process successful. This is especially so in terms of the personal nature of knowledge (for example it is shown that knowledge cannot be imparted to someone in the form of a finished product). It turns out that one must be fully motivated / willing to accept and apply it.

To create an organizational environment in which people are willing to share knowledge, most natural is to develop principles and the concept of continuous improvement, and to nurture a culture of learning. Learning by itself at the individual level signifies an awareness of adaptation, of consciously seeking a solution to a particular situation, or seeking to resolve any conflict between two completely different and dialectically opposed ways of thinking, and conscious and purposeful finding of a solution, or conscious adaptation. Learning as a process in and of itself for the individual as well as the group concerned is a conscious overall personal engagement, a holistic journey, seeking and clearing the unknown, consciously going back and forth, using different ways of reflection and action, of feeling and thinking and application, all in a certain period. It involves the integrated functioning of the whole person - thinking, feeling, understanding and its behaviour towards acquiring new knowledge.

Through learning as a process, there is a synergistic connection between the person / group and the environment. The way the possibilities of each new experience are dealt with determines the range of choices and decisions we see. The choices and decisions we make to a certain degree determine the knowledge we strive to achieve, and this influences our future choices. In essence, learning is a process of knowledge creation (Kolb and Kolb, 2008).

\section{Knowledge management framework researched}

Knowledge management methods are used to enable the enterprise to utilize and develop employee knowledge in a rational and complete way simultaneously. Knowledge management comes as a goal and does not mean only knowledge production, but as a goal-oriented use and development of knowledge and skills that improve the performance of the organization, in order that one becomes more competitive, efficient, and innovative.

Nonaka and Takeuchi (1995) emphasize the difference, departing from the traditional definition of knowledge as "justified true belief", by defining knowledge as "a dynamic process of man towards justified personal belief about "the truth ". (Nonaka and Takeuchi, 1995: 58) According to them, in order to produce new knowledge / innovation, it is necessary to enable knowledge creation beforehand. For them, organizational knowledge creation is "the ability of the company" as a whole to create new knowledge, to spread it too through the organization to incorporate it into its products, services and systems" (Nonaka and Takeuchi, 1995: 58) and explain it through their dynamic "spiral of knowledge concept".

\section{Customized Knowledge Management Cycle Model}

By integrating the LH cycles outlined in the Heisig (2009) reviews one can make a simple, practical and comprehensive LH cycle model. Building on the Evans and Ali's (2013) Lifecycle Model The Knowledge Management Cycle (KMC) is advanced and consists of 7 phases: 1. to 
identify, 2. to preserve, 3. to share, 4. to use, 5. to learn, 6. improve and 7. Create new knowledge here modified into Innovate.

\section{Phase 1. Identifying and / or creating knowledge}

When designing for a specific knowledge request, the researcher must identify whether there is adequate "in-house" knowledge or that necessary knowledge should be created or acquired (either through purchase or through building or both). This is why these two phases are linked and grouped in the Knowledge Management cycle model.

\section{Phase 1.1: Identify knowledge}

What do we want to achieve? What knowledge do we need to have to achieve the desired result? Do we have it and who should transfer / acquire it?

It is a phase in which the intellectual capital and needs of the organization are assessed in defining critical-to-mission-of-organization knowledge and mapping the existing intellectual base for future needs. With effective search for specific knowledge, the identifying phase involves analysing and evaluating specific organizational rules, work cultures and evaluation criteria. According to Wiig (1993), analysis involves looking at and removing / separating what is shown to have value for a viable solution to a particular problem or decision to an existing situation, and breaking down / separating to the end to discover potentially useful knowledge.

\section{Phase 1.2. Development of knowledge, creation of new knowledge}

The knowledge requirement may require a need for new knowledge and has to be built if it is not found in the search phase. Also new knowledge may need to be created, if existing knowledge only partially meets the knowledge needs.

\section{Phase 2: Storage / Storage}

Once the knowledge is judged to be valuable to the organization, based on the analysis and evaluation in the identify phase and the creation phase, it is stored as an active integral part of the organizational memory (in the minds of employees in the form of experience or bases of knowledge data or both). This stage indicates the preservation of a codified form of knowledge in the enterprise databases and embedded knowledge in the products / services of the enterprise. Generally speaking, not all knowledge that holds value for individuals or organizations can be stored in databases. The way they are structured is to help them find the knowledge they want, to find and share the knowledge they want.

Most often these are activities that involve meta-tagging (tagging according to defined tags, or according to a general association for easy retrieval) classification, archiving, linking and optimizing search and retrieval.

\section{Phase 3: Knowledge Sharing}

Knowledge is retrieved / used from organizational memory, and shared / disseminated (shared / shared) both inside and outside the enterprise. The time and frequency (how often) of sharing can be pre-determined (for example, immediately and often as new knowledge is preserved) or on an ad hoc basis (from time to time). Explicit, dynamic and flexible (Wiig, 1993; Meyer and 
Zack, 1999) network of expertise (e.g., a community of shared practice) fosters collaboration and can specifically contribute to organizational knowledge sharing. Sharing tacit knowledge can be done through a variety of initiatives and activities, through mentoring, training, or apprenticeship programs. A balanced selection of technologies and deployment channels should be established in each enterprise according to their strengths and weaknesses (Dalkir, 2011)

\section{Phase 4: Using knowledge}

Once shared, knowledge can be activated, its value can be set apart and applied across the enterprise, and it can serve to solve problems, make decisions, improve efficiency or foster innovative thinking. Knowledge can be embedded (Wiig, 1993), and there will always be some degree of tacit knowledge that is applied. The knowledge application stage is crucial for internalizing the tacit form of knowledge. According to Yuasa (1987: 25) who describes it as a phase so called "learning with the body" and according to Boisot (2002: 73) "learningthrough-doing".

\section{Phase 5: Learning}

The knowledge that was shared and used in the previous stages can be used as a basis for creating new and refining existing knowledge. The use of knowledge, especially in situations where professionals provide contextual understanding, leads employees to gain experience that enables them to interpret the impact of knowledge on their work environment (Evans and Ali, 2013). This stage involves deconstructing (applying) the "blocks" with knowledge, integrating, connecting, combining and internalizing knowledge.

\section{Phase 6: Improving knowledge}

Learning that takes place in the previous phase leads next phase that is further refinement of knowledge. New value is either identified or created by them and additions or updates are made to keep them current in Organizational Memory, to be applicable in the context of organizational performance. Knowledge is repackaged to be stored, archived or labelled (in the case of multiple forms of tacit knowledge) so that their value can be used effectively in the future.

In this model (KMC Model) the improvement phase is the decision about which knowledge is archived, stored or transferred outside the organization / enterprise for future use. Some general activities that help with the improvement phase include: for example, post-crisis review, reflection time, and adaptation lessons learned.

\section{Phase 7: Innovate / create}

This stage is also connected to the first phase by the mere creating and delivering new organizational-level knowledge in innovative enterprise products / services / processes. Creation occurs when prior knowledge is applied or linked in a new way, or a new combination, reflecting new cognitive concepts that arise when employees, inventors, researchers, builders, or entrepreneurs (re) combine most often through teamwork, social interaction, and already existing cognitive concepts acquire new knowledge, which in turn can bring new meaning or meaning. 
In addition to the scope of technological knowledge that it must undoubtedly have, crucial and essential for successful innovation, is the ability of the organization to apply that knowledge (Hansen, Perry, Reese, 2004; Taylor and Greeve, 2006; Volberda and Van Den Bosch, 2005). Knowledge related to innovation activities is analysed in terms of how innovations arise, are created and how knowledge can be organized to influence innovation activities.

The creative process of transferring from the individual to the organization and vice versa, the process of coming up with a feeling to realize a new combination or integrate several existing concepts is a challenge that cannot be fully understood or foreseeable, but if certain practices are used it is likely to happen.

\section{Innovation as a creation}

Here, below, are selected some knowledge management practices that enable the emergence of an innovative process.

Usually, for innovations to be realised, there are previous causes and consequences of new concepts and they certainly do not occur immediately. They are discovered in the process of trial and error, elimination of error, re-examination of concepts, which can take years and are regularly associated with a need for increasing the knowledge base. (Witt Ulrich, 2016)

According to the Oslo Manual (2005), business innovation is defined as "a product, process, marketing method or organizational method that must be new (or significantly improved) for enterprises", while according to Kline and Rosenberg (1986) innovation should be considered "as a series of changes in a system"; Freeman and Soete (1997) distinguish innovation from invention, with the former defining it as "the creation of a new idea and latter bringing it into practice - which includes all the activities needed to commercialize new products / services".

Above mentioned different definitions of innovation state the most important message, which is that innovation must bring something new to the enterprise, national market and global market in order to be considered innovative. Simply said, innovating or being involved in innovation activities helps companies to stay competitive, and that knowledge brings them forward in their respective industries or markets.

Technological, Product and Process (TPP) innovation activities represent all the scientific, technological, organizational, financial and commercial steps that are actually taken to bring about the implementation of technologically new or improved products and processes. Some are highly innovative; others are not so new but needed for realization (Oslo Manual, 2005: 32).

The Oslo Manual (2005) defines innovative activities based on two concepts / approaches, subjective and objective: an innovative enterprise and an innovative activity. According to the subjective approach, an innovative enterprise is an organization that has realized at least one innovation whether it is a product, technology, marketing or process or their combination (Oslo Manual, 2005: 31).

According to the objective approach, the enterprise can have innovative activities without any innovation. All innovative activities can be classified into three categories:

1. "Successful with the result of realizing innovation (although this innovation may also be commercially unsuccessful). 
2. In progress, work in progress that has not yet resulted in the realization of innovation.

3. Abandoned before the realization of innovation" (Oslo Manual, 2005: 10).

The survey undertaken includes innovative activities in enterprises under the previous three categories. Below are the selected samples of the research questions, which are included for measuring the innovative activities of the first category.

An innovative enterprise is defined as an entity that has successfully implemented a technologically new or significantly improved product / service / process or combination of previous ones over a period of time under investigation. This category can be divided into companies that have only "passive" innovative products / services / processes, i.e. those that have exclusively innovated by importing embedded technology into new machinery or equipment. (OECD Oslo Manuel, 2005: 11)

\section{RESEARCH METHODOLOGY}

\section{Primary data collection methods:}

\subsection{Quantitative methods:}

- Survey method of the survey herewith is aimed to obtain primary data from the employees of the selected enterprises with their perception of business practices regarding Knowledge Management and Innovation activities in their respective field of work and enterprises. The primary data obtained are processed and analysed using appropriate statistical methods, such as:

- Method of descriptive analysis - in order to determine the individual demographic and contextual determinants in the enterprises;

- Statistical analysis method using Chi-Pearson distribution - in order to check the observation and perform a fullness test, to determine how well the model and the observation are validated;

\section{EMPIRICAL SURVEY AND FINDINGS}

The research data is collected and analysed from enterprise employees, which in the period under study have introduced an innovative product / service / process in the period from June to December 2017 within selected enterprises (in total 38). Enterprise representatives were contacted and notified by the author via personal contact, telephone or email in addition to a written notice of the purpose of the work. An electronic link was then sent to the firms and / or respondents to the questionnaire created for this survey. Each respondent answered the questions to the best of their knowledge and experience working within the respective company.

Total number of respondents who completed the questionnaire is 176 , whereas 165 responds were complete or $93.75 \%$ of the respondents.

More general approach is applied in order to obtain as much as possible information from the employees of the contacted enterprises that were participating in this research, based on selected key thesis questions, selected from Oslo Manual (2005), and made adjustments to obtain as relevant and qualitative data as possible from the participants. 


\section{Measurement of knowledge management practices}

Question number 4 of the Questionnaire, measuring knowledge management on a personal level: How long does it take to find the information I need?

This states a response at a firmly established or expected time interval (approx.: $<5 \mathrm{~min}, 5-15$ min, up to $30 \mathrm{~min}$, and over $30 \mathrm{~min} . .$. ) for a clearer analysis of the data. If the retrieval of the required data and information from your data base is fast, it is likely that knowledge is used regularly on an individual level - regular data / information management and technical and operational infrastructure knowledge.

Table 1. Survey Question 4 with obtained results

\begin{tabular}{|c|l|c|c|}
\hline IV & $\begin{array}{l}\text { How long does it take to find the information I need } \\
\text { from my file? }\end{array}$ & $\begin{array}{c}\text { Number of } \\
\text { respondents }\end{array}$ & $\%$ \\
\hline 1 & 5 minutes & 108 & $65.45 \%$ \\
\hline 2 & $5-15$ minutes & 44 & $26.67 \%$ \\
\hline 3 & up to 30 minutes & 8 & $4.85 \%$ \\
\hline 4 & longer than 30 & 5 & $3.03 \%$ \\
\hline
\end{tabular}

Source: M. Pendevska, 2019

At the organizational level:

This parameter measures the time it takes to find the information needed in individual database. This enables to obtain additional features for knowledge management practices on an individual level, i.e. accessibility and ease (or lack thereof) in finding the required knowledge, existence or non-existence of a method of finding documents and files to obtain satisfactory or unsatisfactory search results.

At the organizational level: how long does it take to find the information I need from the shared file?

These results probably indicate that established organizational practices and ways of structuring information are clear and easily accessible to their employees. The quick and easy way to get the information you really need, indicates frequent and regular use of established procedures in order to obtain the needed information.

Table 2. Survey Question 5 with obtained results

\begin{tabular}{|c|l|c|c|}
\hline $\mathrm{V}$ & $\begin{array}{l}\text { How long does it take for me to find the information } \\
\text { I need from a shared file in the organization? }\end{array}$ & $\begin{array}{c}\text { Number of } \\
\text { respondents }\end{array}$ & $\%$ \\
\hline 1 & 5 minutes & 53 & $31.52 \%$ \\
\hline 2 & $5-15$ minutes & 77 & $46.67 \%$ \\
\hline 3 & up to 30 minutes & 32 & $19.39 \%$ \\
\hline 4 & longer than 30 & 4 & $2.42 \%$ \\
\hline
\end{tabular}

Source: M. Pendevska, 2019

These results show that established organizational practices, accessibility and frequency of structured information are clear to the ones that need them and are easily accessible on the enterprise level and are regularly used. 


\section{Measuring the results of innovative business activity}

As we try to measure a particular innovation activity, an objective approach is chosen (Oslo Manuel, 2005: 49), i.e., to collect selected data on an innovative activity in an enterprise.

According to the previous definition, the selected questions should be answered:

In accordance with knowledge management practices, what is the result of the operation of enterprises in our country in terms of successful (commercial) realization of innovation, which degree of novelty brings with it the product / service / process that is produced / is provides as a service / technological or organizational process?

This includes the innovations undertaken by enterprises to fulfill certain product / service improvement, manufacturing process or service for more profitable operation. It shows the enterprise's commitment to incremental product / service / process improvement or the introduction of a radically new product / service / process. It is assumed that incremental innovation / improvement of product / service / process quality extends the product / service / process life cycle. Most of the innovations are probably in this section.

To get initial information on enterprise innovation activities complete the following basic company information and innovative product or services:

Table 3. Survey Question 14 with obtained results

\begin{tabular}{|c|l|c|c|}
\hline XIV & Realized innovation in the company where I work? & $\begin{array}{c}\text { Number of } \\
\text { respondents }\end{array}$ & $\%$ \\
\hline 1 & Product & 62 & $37,58 \%$ \\
\hline 2 & Service & 66 & $40.00 \%$ \\
\hline 3 & Working process & 37 & $22.42 \%$ \\
\hline
\end{tabular}

Source: M. Pendevska, 2019

Measuring the novelty incorporated in their respective products indicates the knowledge incorporated within the product / service / process.

How new are the product / service / process in the company, product / service / process?

Table 4. Survey Question 15 with obtained results

\begin{tabular}{|c|l|c|c|}
\hline $\mathrm{XV}$ & This product/service/process is: & $\begin{array}{c}\text { Number of } \\
\text { respondents }\end{array}$ & $\%$ \\
\hline 1 & New worldwide & 23 & $13.94 \%$ \\
\hline 2 & New to the market in the state & 52 & $31.52 \%$ \\
\hline 3 & New for the organization & 90 & $54.55 \%$ \\
\hline
\end{tabular}

Source: M. Pendevska, 2019

This shall indicate if the commitment within the enterprise is crowned with a product that is new to the enterprise, to the national market or worldwide. A new product for the organization shows low level of the applied knowledge (knowledge already used and known in the near environment) that organization can process and apply.

New product in the country means bringing new knowledge in the national market that is applied in a product and does not exist within the country, in the near environment. This means 
the enterprise has contacts with wider business environment and is competitive in wider region bringing its knowledge base higher. When an enterprise develops this kind of knowledge / product, i.e. has a wide range of in-state and out-of-state contacts / associates, it indicates that the enterprise is competitive at the state or regional level.

A new product globally demonstrates enterprise-wide knowledge base with cutting edge of technology development and their application in practice. The role of these enterprises is considered as leaders in their field and their activity makes them globally recognizable.

The degree of novelty indicates whether the product is radically new, that is, it creates its own new market, or making incremental adjustments in order to maintain its market longer.

What degree of innovation a product / service / process has, and a novelty of innovation?

Table 5. Survey Question 16 with obtained results

\begin{tabular}{|c|l|c|c|}
\hline XVI & $\begin{array}{l}\text { Level of innovation in a new } \\
\text { product/service/process: }\end{array}$ & $\begin{array}{c}\text { Number of } \\
\text { respondents }\end{array}$ & $\%$ \\
\hline 1 & High degree (over 60\%) & 47 & $28.50 \%$ \\
\hline 2 & Intermediate degree (or 30-60\%) & 89 & $53.90 \%$ \\
\hline 3 & Low (or up to 30\%) & 29 & $17.60 \%$ \\
\hline
\end{tabular}

Source: M. Pendevska, 2019

These parameters measure the novelty of the product, whether it is incremental innovation in the products / services / processes or is it radical.

\section{Analysis of the Relationship between Knowledge Management and the Level of Innovation with Chi-square Analysis}

Previous data show business performance of surveyed enterprises with selected research questions.

From the survey sample obtained, enclosed are selected questions from the Survey Questionnaire cross-checked to establish a relation, to determine more clearly if there exists a relation between the selected questions from the Questionnaire.

This indicator is taken as a starting point, as it can show more clear defining tendency between obtained results.

Below one tests the null hypothesis and the alternative hypothesis as following:

H.0.1: There is no correlation of the answers to question 4, the speed of finding the necessary information on a personal level with question 14, i.e. they are independent (no relation).

H.1.1: There is a correlation of the answers to question 4, the speed of finding the necessary information on a personal level with question 14, i.e. they are dependent (there is a relation).

The analysis of the Likelihood Ratio p value is 0.027 which means that it is at the $95 \%$ significance level and the H.1.1 hypothesis for interdependence or existence of interdependence will be accepted; or, there is a relation on the speed of finding information with delivering an innovative product / service / business process. 
This may indicate that from the sample analysed the high degree of knowledge management system at an individual level influences the realization of an innovative product / service / business process within the enterprises.

Table 6. Relation between survey question 4 and survey question 14

\begin{tabular}{|c|c|c|c|c|c|c|}
\hline \multicolumn{7}{|c|}{ Factor $1 *$ Factor 2} \\
\hline \multirow{2}{*}{ Factor 1} & \multirow{2}{*}{\multicolumn{2}{|c|}{ Factor 2}} & \multicolumn{3}{|c|}{ The innovation from your enterprise } & \multirow{2}{*}{ Total } \\
\hline & & & product & process & service & \\
\hline \multirow{8}{*}{$\begin{array}{l}\text { How long } \\
\text { do I need } \\
\text { to find } \\
\text { information } \\
\text { that I need } \\
\text { from my } \\
\text { data base? }\end{array}$} & \multirow{2}{*}{5 minutes } & replies & 42 & 22 & 44 & 108 \\
\hline & & $\%$ of total & $25.5 \%$ & $13.3 \%$ & $26.7 \%$ & $65.5 \%$ \\
\hline & \multirow{2}{*}{$\begin{array}{l}5-15 \\
\text { minutes }\end{array}$} & replies & 16 & 7 & 21 & 44 \\
\hline & & $\%$ of total & $9.7 \%$ & $4.2 \%$ & $12.7 \%$ & $26.6 \%$ \\
\hline & \multirow{2}{*}{$\begin{array}{l}\text { up to } 30 \\
\text { minutes }\end{array}$} & replies & 2 & 5 & 1 & 8 \\
\hline & & $\%$ of total & $1.2 \%$ & $3.0 \%$ & $0.6 \%$ & $4.8 \%$ \\
\hline & \multirow{2}{*}{$\begin{array}{l}\text { longer than } \\
30 \text { minutes }\end{array}$} & replies & 2 & 3 & 0 & 5 \\
\hline & & $\%$ of total & $1.2 \%$ & $1.8 \%$ & 0.0 & $3.0 \%$ \\
\hline \multirow{2}{*}{ Total } & & replies & 62 & 37 & 66 & 165 \\
\hline & & $\%$ of total & $37.6 \%$ & $22.4 \%$ & $40.0 \%$ & $100.0 \%$ \\
\hline
\end{tabular}

Source: M. Pendevska, 2019

Below one tests the 2.0 hypothesis and the alternative hypothesis 2.1 as following:

H.2.0: There is no correlation of the answers to Survey Question 4, the speed of finding the necessary information at personal level with Survey Question 15, i.e. they are independent (no relation).

H.2.1: There is a correlation of the answers to Survey Question 4, the speed of finding the necessary information on a personal level with Survey Question 15, i.e. they are dependent (there is a relation).

Table 7. Relation between survey question 4 and survey question 15

\begin{tabular}{|c|c|c|c|c|c|c|}
\hline \multicolumn{7}{|c|}{ Factor $1 *$ Factor 2} \\
\hline \multirow[b]{2}{*}{ Factor 1} & \multicolumn{2}{|l|}{ Factor 2} & \multicolumn{3}{|c|}{ This product/service/process is: } & \multirow[b]{2}{*}{ Total } \\
\hline & & & $\begin{array}{c}\text { new to the } \\
\text { organization }\end{array}$ & $\begin{array}{c}\text { new to the } \\
\text { national level }\end{array}$ & $\begin{array}{c}\text { new on a } \\
\text { global level }\end{array}$ & \\
\hline \multirow{8}{*}{$\begin{array}{l}\text { How long } \\
\text { do I need } \\
\text { to find } \\
\text { information } \\
\text { that I need } \\
\text { from my } \\
\text { data base? }\end{array}$} & \multirow{2}{*}{5 minutes } & replies & 59 & 33 & 16 & 108 \\
\hline & & $\%$ of total & $35.8 \%$ & $20.0 \%$ & $9.7 \%$ & $65.5 \%$ \\
\hline & \multirow{2}{*}{$\begin{array}{l}5-15 \\
\text { minutes }\end{array}$} & replies & 23 & 18 & 3 & 44 \\
\hline & & $\%$ of total & $13.9 \%$ & $10.9 \%$ & $1.8 \%$ & $26.7 \%$ \\
\hline & \multirow{2}{*}{$\begin{array}{l}\text { up to } 30 \\
\text { minutes }\end{array}$} & replies & 4 & 0 & 4 & 8 \\
\hline & & $\%$ of total & $2.4 \%$ & $0.0 \%$ & $2.4 \%$ & $4.8 \%$ \\
\hline & \multirow{2}{*}{$\begin{array}{l}\text { longer than } \\
30 \text { minutes }\end{array}$} & replies & 4 & 1 & 0 & 5 \\
\hline & & $\%$ of total & $2.4 \%$ & $0.6 \%$ & $0.0 \%$ & $3.0 \%$ \\
\hline \multirow{2}{*}{ Total } & & replies & 90 & 52 & 23 & 165 \\
\hline & & $\%$ of total & $54.5 \%$ & $31.5 \%$ & $13.9 \%$ & $100.0 \%$ \\
\hline
\end{tabular}

Source: M. Pendevska, 2019

The analysis of the Likelihood Ratio p value is 0.021 which means that it is a the $95 \%$ significance level and the hypothesis H.2.1 for interdependence or existence of interdependence will be accepted. 
Innovation in a product / service / process brings different levels of innovation, in-built knowledge or how much new knowledge is used in the relevant innovative products / processes / service and defines categories "new to the organization.", "New to the market in the country" and" new worldwide".

The knowing where to find knowledge needed and used in innovative products shows the tendency of persistence of the company to develop its own business. The higher the knowledge applied to their products shows probably higher the novelty of innovation embedded in the products / services / business process.

It is noticeable the relatively low level of knowledge embedded in the innovative product or most of the answers with $54.5 \%$, and the level of utilization of the knowledge management system with $35.8 \%$ or $13.9 \%$, but up to $30 \mathrm{~min}$. with $2.4 \%$ and over $30 \mathrm{~min}$. with $2.4 \%$.

It is also noticeable that in the categories "new to the state market" and "new to the world level" the search for information belongs to the two high groups, i.e. "up to $5 \mathrm{~min}$ " with $20.0 \%$ and 9.7\% respectively, and for the "5-15 min" category $10.9 \%$ and $1.8 \%$;

\section{CONCLUSION}

Starting from the humanistic approach that every change starts from the individual and his knowledge and ability, and by identifying the established knowledge management infrastructure in the enterprise, the current situation in the enterprises is identified. The model used clearly reflects the ability of enterprises to utilize their knowledge, foster a personal and organizational system for creating, transferring, storing and reusing knowledge. This section shows the level of use of systems, creating, transmitting, storing and reusing information, gives a good explanation of the level of mutual understanding at different levels in the enterprise. The framework provided aims to identify the current situation in order to provide a basis for explaining the key elements that describe operational and strategic compliance. The results are in line with previous research in this area. Namely, it indicates that there are knowledge management practices, but they are used at a very low level.

Knowledge management practices in a broad sense do not exist for themselves. The purpose of knowledge is to be used. For enterprises this dimension of knowledge is especially critical for their survival and further development, that is, capturing as much as possible of the knowledge of their employees, incorporating it with existing ones or outside them into new enterprise products / services.

Since new knowledge does not occur by accident nor does it appear, it means that it exists somewhere and should be used in the interest of the enterprise. Their level and the way companies do it are dimensions that are explored and included in last part of the Questionnaire. Logically, this part explores various parameters for the existence of innovative activities in the enterprise, i.e. commercialization of new knowledge of the enterprise.

The second part of the Questionnaire actually completes the research in enterprises, which is the result of using their (and external) knowledge in innovative activity.

In management literature, innovative activities are elaborated as the main strategy for gaining competitive advantage and generating sustainable profits. The criterion for positive evaluation of innovation and its effects is based on the innovations that pass the market test successfully. 
The willingness of the enterprise to deal with rapid change is related to the creation of new knowledge / innovative products / services, it is the path that enables continuous learning. Every technological change result in innovative activities, raising the level of knowledge, including intangible investments such as research and development. The main challenge, of course, is to create conditions within the enterprise for long-term sustainable efforts for innovative activities.

The empirical research data mark changes at the enterprise level, the interaction between different stakeholders, both at the individual level and the organizational level. It shows different types of collaboration and knowledge-sharing in terms of new knowledge, practices that lead to the realization of new products / services / processes in the form of innovation in the current business environment.

For that to happen, there is probably a demand for those innovations. There are cases where they offer solutions to problems that have not previously been satisfactorily resolved. In most cases, the demand for innovation is simply due to lower cost, better quality and / or more favourable supply conditions. If innovations pass the market test successfully, it means that the demand for innovation pays off, and the innovator can make a profit. For this reason, innovations that successfully pass the market test are considered to improve well-being and are therefore highly desired.

Finally, recommendations arising from the empirical research on knowledge management practices and their impact on the creation of new knowledge in the form of new products / services / processes in enterprises in the Republic of North Macedonia show that this area is under-researched and has substantial practical value to enterprises in order to enhance their ability to perform successful innovation.

\section{REFERENCES}

Dalkir, Kimiz. 2005. Knowledge Management in Theory and Practice. Butterworth Heinemann. Vol. 4. https://doi.org/10.1002/asi.21613.

Evans, Max, Kimiz Dalkir, and Catalin Bidian. 2014. "A Holistic View of the Knowledge Life Cycle: The Knowledge Management Cycle (KMC) Model." Electronic Journal of Knowledge Management 12 (2): 85-97.

Heisig, Peter. 2013. “Knowledge Management - Step by Step Knowledge Management - Step by Step • Background $\bullet$ Concepts $・$ Knowledge Management - Step by Step Report from Business Practice $\bullet$ Concepts $\bullet$ Summary," no. January: 1-7.

Heij C. V. 2015. Innovating beyond Technology, ERIM PhD Series in Research in Management, 370 ERIM reference number: EPS-2015-370-S\&E ISBN 978-90-5892418-6

Kolb, Alice Y, and David a Kolb. 2008. "Experiential Learning Theory: A Dynamic, Holistic Approach to Management Learning, Education and Development." Handbook of Management Learning, Education and Development, 1-59. https://doi.org/http://dx.doi.org/10.4135/9780857021038.n3.

Kok, J.A.2005, Can models for knowledge management be successfully implemented to manage the diversity of indigenous knowledge?

Nonaka, I., Takeuchi, H. (1995): The Knowledge-Creating Company: How Japanese Companies Create the Dynamics of Innovation, Oxford University Press, May, (1995:58)

Nonaka, Ikujiro, and Noboru Konno. 1998. "The Concept of 'Ba.'” California Management Review. https://doi.org/10.1016/j.otsr.2010.03.008. 
Nonaka, Ikujiro, and Ryoko Toyama. 2003. "The Knowledge-Creating Theory Revisited: Knowledge Creation as a Synthesizing Process." Knowledge Management Research \& Practice 1 (1): 2-10. https://doi.org/10.1057/palgrave.kmrp.8500001.

Minbaeva, Dana B., Kristiina Mäkelä, and Larissa Rabbiosi. 2010,” Explaining IntraOrganizational Knowledge Transfer at the Individual Level" Center for Strategic Management and Globalization Copenhagen Business School -Working Paper No. $1 / 2010$. http://openarchive.cbs.dk/bitstream/handle/10398/8001/SMGWP2010_1.pdf?sequence= 1.

Mcelroy, Mark W. 2001. "Second-Generation Knowledge Management."

North, K., Probst, G., Romhardt, K. (1998): Wissenmessen - Ansätze, Erfahrungen und kritische Fragen, in Zeitschrift für Führung und Organisation, Vol. 3

Michailova, Snejina, and Kate Hutchings. (2004) "Knowledge Sharing and National Culture: A Comparison Between China and Russia" Journal of Management Studies.

Oslo Manual, 2005, OECD 2005. "Oslo Manual." http://www.oecd.org/science/inno/2367580.pdf.

Pendevska Marija, (2019), "The Influence of knowledge management on the innovation in the enterprises in Republic Macedonia", doctoral thesis, defended June 2019 at Faculty of Economy, University Cyril and Methodius Skopje.

Probst, G., Raub, S., Romhardt, K. (2000): Managing Knowledge, John Wiley \& Sons, Chichester

Resatsch Florian, Faisst Ulrich 2003, "Measuring the Performance of Knowledge Management Initiatives." n.d.

Wiig K.M, 1993, Knowledge Management Foundations: Thinking about Thinking: How People and Organizations Create, Represent and Use Knowledge.

Willke H, 1998. Systematisches Wissenmanagement, Stuttgart: Lucius und Lucius 1998: 39

Witt, Ulrich. 2016. "What Kind of Innovations Do We Need to Secure Our Future?" Journal of Open Innovation: Technology, Market, and Complexity 2 (1): 17. https://doi.org/10.1186/s40852-016-0043-y.

Witt, Ulrich, Tom Broekel, and Thomas Brenner. 2007. "Knowledge and Its Economic Characteristics - A Conceptual Clarification." Ssrn. https://doi.org/10.2139/ssrn.1019222. 